\title{
Lucinid bivalves from Miocene hydrocarbon seep sites of eastern North Island, New Zealand, with comments on Miocene New Zealand seep faunas
}

Kazutaka Amano, Crispin T.S. Little, and Kathleen A. Campbell

Acta Palaeontologica Polonica 63 (2), 2018: 371-382 doi:https://doi.org/10.4202/app.00461.2018

Three new fossil species of lucinids, Meganodontia haunuiensis, Elliptiolucina neozelandica, and Lucinoma saetheri, are described from lower to middle Miocene hydrocarbon seep carbonates from north and south of Hawke Bay, eastern North Island, New Zealand. Of these taxa Meganodontia haunuiensis is confined to seep sites south of Hawke Bay, while Elliptiolucina neozelandica comes only from the seep sites north of Hawke Bay. Using ecological information from modern bivalve species, we suggest the southern area seep sites formed in shallower waters than the northern sites. Among the lucinids, Meganodontia haunuiensis is one of the oldest records of the genus, and its distribution has shrunk from worldwide in the Miocene times to only around Taiwan today. Elliptiolucina neozelandica is the second oldest species in the genus. Since the Miocene the distribution of Elliptiolucina has narrowed but its habitat range has increased to both seeps and sandy environments, mainly around the Philippines.

Key words: Mollusca, Bivalvia, Lucinidae, hydrocarbon seep, Miocene, New Zealand.

Kazutaka Amano [amano@juen.ac.jp], Department of Geoscience, Joetsu University of Education, 1 Yamayashiki, Joetsu 943-8512, Japan. Crispin T.S. Little [earcts1@leeds.ac.uk], School of Earth and Environment, University of Leeds, Leeds LS2 9JT, UK. Kathleen A. Campbell [ka.campbell@auckland.ac.nz], School of Environment, Faculty of Science, University of Auckland, Private Bag 92019, Auckland Mail Centre, Auckland 1142, New Zealand.

This is an open-access article distributed under the terms of the Creative Commons Attribution License (for details please see creativecommons.org), which permits unrestricted use, distribution, and reproduction in any medium, provided the original author and source are credited. 
PoF Full text $(645.8 \mathrm{kB})$ 